\title{
PRUDENCIO GALINDO Y EL PROBLEMA DE LA PREDESTINACIÓN
}

\author{
Marcelino Ocaña García \\ Universidad Complutense de Madrid
}

\section{RESUMEN}

Un nombre propio y un tema, se quieren poner de relieve en este artículo. El nombre, Prudencio Galindo: español, - y como tal, casi ignorado-, que tuvo la osadía de defender a un fraile poco apreciado, Gotescalco, para lo que no rehuyó el enfrentarse, tanto al poder eclesiástico, - Hincmaro y Rabano Mauro-, como al prestigio intelectual, representado por Escoto Eriúgena. La oportunidad, un tema de todos los tiempos, desde la aparición del cristianismo, ya debatido por San Agustín: el intento de armonizar el libre albedrío con la predestinación y la gracia.

Palabras clave: conciliación, libre albedrío, predestinación, gracia, doble predestinación.

\begin{abstract}
I want to bring to the attention of the reader in this essay. A proper Name and a certain topic. The Name, Prudencio Galindo, Spanish - and therefore Almost forgotten - who dared to defend a little appreciated friar, Gotescalco, so much so that he did not avoid opposing not only eclessiastical power -Hincmaro and Rabano Mauro- but also the prestigious scholar Scotus Eringenus. The opportunity, a topic of all times, from the beginning of Christianity, already discussed by St. Augustine: the intention of harmonizing free will with predestination and grace.
\end{abstract}

Key words: Conciliation, free will, predestination, double predestination.

\section{INTRODUCCIÓN}

«Nuestra filosofía, —dice Unamuno-, está líquida y difusa en nuestra literatura, en nuestra vida, en nuestra acción, en nuestra mística sobre todo, y no en sistemas filosóficos». Los escolásticos más metafísicos han sido igualmente teólogos; y siempre han buscado la conciliación y armonía entre la razón y la fe, bien que en su intento, no siempre llegaron a conclusiones coincidentes.

Tenemos un caso bien elocuente en la llamada «polémica de auxiliis», ocurrida, como bien se sabe, en la España del siglo XVI: dos posturas, unidas sin duda en la misma fe, que se contraponen, sin posibilidad de conciliación, al tratar de explicar sus respectivas convicciones.

Dos puntualizaciones, al respecto: primero, que el enfrentamiento «Báñez-Molina» no fue una controversia meramente teológica, por más que este enfoque haya servido de excusa para 
obviarlo en muchos tratados, como por ejemplo, Copleston;, segundo, que esta «anécdota» para más de uno, va siendo tenida cada día más en cuenta, como auténtica «categoría», a medida que se van estudiando y divulgando los respectivos planteamientos, desde perspectivas auténticamente filosóficas.

Hoy nos vamos a remontar al siglo IX. Veremos allí un precedente de este problema, no sólo en cuanto al fondo temático, sino, incluso, en cuanto a la forma virulenta en que se desarrolló. El protagonista, un español, como de costumbre desconocido u olvidado.

\section{LA POLÉMICA DE LA PREDESTINACIÓN EN EL SIGLO IX}

\subsection{Precisiones terminológicas}

Puede que la mayoría de los términos que estamos utilizando sean de dominio y uso común. No obstante, no estará de más, puntualizar algunos conceptos que, de no ser entendidos y utilizados adecuadamente, pueden llevarnos a un desajuste del problema y a una intelección equivocada del mismo. Me ceñiré, evidentemente, a los indispensables.

\subsubsection{Libertadlibre albedrío}

Es obligado comenzar por estos términos, no sólo por ser los más genuinamente filosóficos, sino porque con frecuencia se emplean como sinónimos, y también, porque el llamado «libre albedrío» pueda ser considerada una expresión vacía de contenido, cayendo en el desprestigio, al asociarlo a mentes ya trasnochadas de hábito talar y formación escolástica. Sin embargo, la realidad es muy distinta. Resulta que el libre albedrío es lo intrínseco y fundante de lo específicamente humano. Y eso es así, hasta el punto de que, en frases de San Agustín, ni Dios podía arrebatárselo al hombre. Es esa característica la que posee la voluntad, en base a su racionalidad, para poder elegir.

Sin el libre albedrío, la llamada «libertad» no pasa de ser una mera denominación extrínseca, un mero título adjudicado arbitrariamente, por una especie de metáfora lingǘstica, como cuando decimos que una piedra soltada en el vacío desde un quinto piso «cae libremente», o que el agua se desliza en «libertad» desde la fuente.

Supuesto el libre albedrío, la libertad, no es sólo que tiene sentido, sino que es la condición indiscutible para poder hablar de acciones verdaderamente humanas. El libre albedrío siempre acompaña al hombre; es una «potencia activa» capaz de autodeterminación, no determinada ad unum. La libertad, en cambio, es un requisito que debe acompañar al libre albedrío para que éste pueda asumir la responsabilidad de un acto determinado. El libre albedrío es único, aunque multiforme: abarca todos y cada uno de los actos humanos; la libertad es casual y unidireccional. Puede ocurrir que tengamos libertad de reunión, pero no de cátedra o de expresión, o a la inversa.

1 «No deseo decir gran cosa sobre ese tema, puesto que la controversia tuvo un carácter primordialmente teológico. Pero creo que debe ser mencionada por sus implicaciones filosóficas [...]; podría quizá sugerirse que el movimiento general humanístico del Renacimiento tuvo su reflejo, hasta cierto punto, en el molinismo» Copleston, F. Historia de la Filosofia, Barcelona, Ariel, 1975, III, pp. 327-328. 


\subsubsection{Gracia habitual/gracia actual}

La palabra «gracia» es uno de los términos que más nos pueden confundir, si no delimitamos, desde el comienzo, su doble y equícova acepción. «Gracia» apunta a la absoluta gratuidad de quien la concede, --Dios--, nunca obligado por nada ni por nadie. Lo único, -y aquí es donde hay que hacer hincapié-, es que hay dos tipos de gracia, absolutamente diferentes, y que no siempre se atiende a su distinción, por lo que se puede crear el equívoco a que antes aludía. Y es que, una cosa es la «gracia habitual», y otra muy distinta, la «gracia actual». ${ }^{2}$

La gracia habitual hace alusión a un estado permanente de la persona; a un título por el que, quien lo posee, tiene derecho a la «herencia eterna», entra a formar parte de la familia divina, lo mismo que el niño «adoptado» por un matrimonio, que a partir de ese momento tiene los mismos derechos y herencias que el hijo natural. La gracia «actual» es un auxilio circunstancial, pasajero, otorgado para superar una dificultad concreta, para tomar una decisión en un momento especialmente delicado.

A partir de esta distinción todo queda más claro. Es evidente que sin la gracia habitual nadie puede salvarse, porque sin dicha gracia, - título, injerto vital, transformación sobrenatural de nuestra constitución humana-, nadie puede ser reconocido de la familia de Dios. Sobre esto no hay duda. Ahora bien, ¿cómo se consigue, - caso de estar en pecado o de ser «infiel»— o se mantiene esa gracia? Pues bien, para conseguirla o para conservarla, es para lo que, se considera absolutamente necesario el que Dios brinde otro tipo de gracia, — «auxilio» específico-, la «gracia actual».

\subsubsection{Providencia/Predestinación}

Por dos razones se impone precisar el concepto de providencia: la primera, porque la predestinación, —objeto directo de este estudio—, no es sino un caso concreto de providencia, - «quaedam pars providentiae» que dice Santo Tomás -;3 y la segunda, porque el sentir popular ha tergiversado un tanto su concepto, y puede crear confusiones, ya que el «si Dios quiere», o el «Dios escribe derecho con renglones torcidos» del vulgo, puede conseguir hacer creer que todo lo que ocurre, sin excepción, es porque Dios así lo ha dispuesto, dado que su providencia lo acapara absolutamente todo. Sin embargo, la providencia consiste en la disposición de los medios a un fin. Ahora bien, el que los medios obtengan inexorablemente el fin, ya no está exigido por la providencia, entre otras cosas, porque Dios ha organizado el mundo, supeditando unas cosas a otras, otorgando categoría de causas a las creaturas, y respetando el libre albedrío humano.

«Destinar, dice Santo Tomás, ${ }^{4}$ es enviar»; de donde, predestinar no es otra cosa que enviar con antelación, asignar un fin previamente a que se hayan puesto los medios para conseguirlo. En concreto podemos definirla con San Agustín, diciendo que es «la presciencia y preparación de los beneficios de Dios, con que certísimamente se salvan todos los que se salvan». ${ }^{5}$

Si junto a este tipo de predestinación, - predestinación a la salvación-, hablamos de una predestinación negativa o de predestinación a la condenación, - llamada también reprobación-, estamos aludiendo a la denominada «doble predestinación», a que se refieren los textos que citaremos posteriormente.

2 Santo Tomas: Summa Theologica, I-II, q. 109, a. 9: «utrum ille qui iam consecutus est gratiam, -es decir, la gracia habitual-, possit operari bonum, absque alio auxilio gratiae», -gracia actual-. Y en el art. siguiente, «utrum homo in gratia constitutus indigeat auxilium gratiae ad perseverandum».

$31, \mathrm{q} .23$, a. 1 .

4 I, q.23, a. 1.

5 De dono perseverantiae, c. $14, n^{\circ} 35$. 


\subsection{Precisiones históricas}

Desde un punto de vista cronológico, los acontecimientos de que vamos a dar cuenta se desarrollaron a mediados del siglo IX. Desde una perspectiva geográfica, hemos de situarnos en territorio francés. Los telones de fondo son los vistosos y llamativos reclamos del Renacimiento Carolingio. Los múltiples actores que corretean por la Escuela Palatina tendremos que reducirlos, si no queremos perdernos en laberintos sin fin y en textos interminables, a los cuatro o cinco más representativos del drama que pretendemos exponer: Gotescalco, Hincmaro, Escoto Erígena y, por supuesto, Prudencio Galindo; entre bambalinas, con un papel más bien secundario en esta ocasión, podemos descubrir a Rabano Mauro, prestigioso personaje y de gran influencia, pero que, ya viejo y enfermo según propia confesión, no tiene demasiadas ganas de entrar en polémicas, y el también español, Diácono de Lyon, Floro, quien se puso de parte de Prudencio Galindo.

El Renacimiento Carolingio tiene sus preliminares en Pipino el Breve y sus esfuerzos por fomentar el estudio en los monasterios, así como el dar prestigio a la ya existente escuela palatina, donde precisamente se formó Carlomagno, que fue quien, en definitiva dio nombre al movimiento así como las directrices básicas de un ambicioso proyecto que tuvo su momento culminante en los reinados de Ludovico Pío y Carlos el Calvo, durante cuyo mandato, precisamente, tuvieron lugar los sucesos a que nos referimos.

El Renacimiento Carolingio, como más tarde el Renacimiento Humanista, tiene su mirada puesta en el pasado, en la admiración por los modelos antiguos de Grecia y de Roma. No fue un movimiento popular, de masas, sino minoritario, aristocrático, de élites; de ahí el interés por conseguir la flor y nata de la intelectualidad de aquél entonces, para erigirlos en maestros capaces de formar todo un estilo, no ya sólo literario o dialéctico, sino, fundamentalmente cristiano; ya que, para ellos, en esos momentos, era el cristianismo, cuyos valores, por ser eternos y supraterrenos, están muy por encima de la belleza de los versos latinos, o de la contundencia de los planteamientos helénicos, a nada de lo cual se renuncia a la hora de enfrentarse a cualquier problema, pues, como dice el Profesor Rábade, «en el renacimiento carolingio se encuentra toda la temática de los dos siglos y medio que preceden al momento de plenitud de la escolástica». ${ }^{6}$

\subsection{Los hechos}

Comencemos por Gotescalco, ya que fue él, en definitiva, el promotor de la contienda. Gotescalco fue un monje a la fuerza. Sus padres lo ofrecieron como tal, pero él se negó, llegado a la mayoría de edad, a ratificar sus votos. De poco le sirvió, pues, a pesar de que el Concilio de Maguncia le dio la razón, el abad del monasterio en cuestión -Fulda - que no era otro que el propio Rabano Mauro, basado en su Liber de oblatione puerorum, que admitía como válida la oblación hecha por los padres en nombre de los hijos, se opuso y lo retuvo. Ante semejante situación, Gotescalco optó por huir de aquél monasterio y, dado que no tenía más remedio que profesar, lo hizo en el monasterio de Orbais, donde se dedicó al estudio de San Agustín, llegando a la conclusión de que en Dios había una doble predestinación: una para la salvación y otra para la condenación. Este fue el momento en que se destapó la caja de los truenos: Rabano Mauro consigue que el 
Concilio de Maguncia condene la doctrina de Gotescalco y el Obispo de Reims, Hincmaro, desconcertante e incomprensiblemente duro, hace que lo encierren durante siete años, no sin antes haberlo azotado y depuesto de su dignidad sacerdotal.

Posiblemente este comportamiento necesitase una justificación. Por eso, tal vez, veamos al obispo Hincmaro, no sólo aireando las proposiciones de Gotescalco que, según él habían sido causa, tanto de la condenación dogmática como del castigo impuesto al «monje de hábito, pero de mente ferina», como él definía al degradado Gotescalco. Pretendió, inclusive, ver sus tesis, —expuestas en su tratado De praedestinatione Dei et libero arbitrio, dedicado al propio Carlos el Calvo-, y su actitud respaldadas por alguien de prestigio, para lo cual se puso en contacto, entre otros, con nuestro Prudencio Galindo. Este, contra lo que se pudiera esperar, comenzó por implorar clemencia para el desdichado monje, y a renglón seguido redactó una Epistola ad Hincmarum et Pardulum, en la que, sorprendentemente para Hincmaro, defiende con toda naturalidad la doble predestinación con textos, no sólo de San Agustín, sino de San Fulgencio, San Gregorio o San Próspero.

El frente se abrió con dureza. De una parte, Hincmaro, Rabano y Padulo, acusando de hereje a Prudencio. De otra, junto a nuestro obispo, el Diácono Floro de Lyon y Servato Lupo, discípulo de Rabano, entre otros. Ante semejante desconcierto en la doctrina y agresividad en las formas, el rey no tuvo más remedio que intervenir. Para lo que no tuvo mejor idea que acudir a Escoto Erígena, bien que sin sospechar que iba a ser peor el remedio que la enfermedad.

Escoto Erígena, el filósofo más destacado de su tiempo que, según Menéndez y Pelayo, «sabía hasta griego» llegó a Francia procedente de Irlanda, reclamado por el propio rey Carlos el Calvo. No es del caso, remitirnos a su sistema, panteísta y coherente, ni a su estima por la razón y el método. Basta, por ahora, aludir a su tratado De divina praedestinatione, que es donde pretende dar contestación a la demanda exigida por el rey y esperada por los contendientes del momento, aunque lo único que consiguió fue dejar descontentos a ambos bandos y «echar más leña al fuego», como dice Menéndez y Pelayo. El escrito de Escoto tuvo inmediata y cumplida contestación en la pluma de Prudencio, con su escrito De praedestinatione contra Joannem Scotum cognomento Erigena, seu Liber Joannis Scoti correctus a Prudentio, sive a caeteris Patribus, videlicet, a Gregorio, Hieronymo, Fulgentio atque Augustino, cuyo título, aunque largo, se queda bastante corto ante la extensión de la obra que triplica la de Escoto.

\section{LA INTERVENCIÓN DE PRUDENCIO GALINDO, OBISPO DE TROYES}

\subsection{Bio-bibliografía}

Prudencio Galindo, por sobrenombre «Galindón». Aunque nacido en España, - Hesperia genitus, o Hispaniae genitus, según propia confesión-, y probablemente aragonés, no tenemos muchas noticias de su vida hasta que se dio a conocer en la Corte de Ludovico Pío, donde fue nombrado capellán palatino; bien que su fama la consiguió en tiempos de Carlos el Calvo. Hacia el año 844-45 fue nombrado Obispo de Troyes, donde es venerado como santo, al menos «desde el siglo XIII», según Menéndez y Pelayo. ${ }^{7}$ Se fue a Francia, — «Celtas deductus»-, al parecer, comisio- 
nado junto con Lupo el abad de Ferrieres, para reformar el estilo de vida de determinados monasterios. Tenía un hermano, obispo como él, al que se dirige en una de sus cartas, que permaneció en España. Parece que asistió, ya como obispo, al Concilio de París del año 846, tres años más tarde al Sínodo celebrado en la misma ciudad y en el año 853, al acudir al de Soissons fue designado juez y árbitro por los sacerdotes de la diócesis de Reims, —de donde era obispo Hincmaro—, para esclarecer sus diferencias y acercar sus posiciones.

Es denominado «teólogo polemista y erudito», escritor incansable, que «sólo dejó la pluma con la muerte», al que hay que evocar inevitablemente cada vez que se pretenda aludir al tema de la predestinación, o cuantas veces se hable de Gotescalco o Escoto Erígena. Menéndez y Pelayo recoge frases de elogio de diferentes autores, tales como «príncipe de todos los literatos de su tiempo, varón de sumo juicio y muy sabedor de la antigüedad».

Con respecto a sus obras, conviene advertir el tono «sereno y hasta amigable» empleado en su carta a Hincmaro, y la soltura con que cita, sobre todo a San Agustín, no menos que la contundencia con que apoya la tesis de la doble predestinación, defendida por Gotescalco. Y no sólo eso, sino la eficacia de su argumentación, al haber conseguido la exculpación de Gotescalco, junto a la aceptación de la doble predestinación, en los Concilios Valentiniano y Lugdunense, del año 855. Por lo que se refiere a su otra gran obra sobre la predestinación, -la escrita contra Escoto-, hay que poner de relieve, no ya su minuciosidad al contestar una a una a las diecinueve proposiciones sospechosas de herejía, sino, sobre todo, la erudición teológica, la solidez de razonamiento y la precisión en las fórmulas, que consiguieron de Nicolás I, en el 859, la incondicional aprobación de su doctrina, no obstante haber sido ésta puesta en tela de juicio, tanto por Hincmaro como por el ya desaparecido Rabano Mauro.

Junto a estas dos obras, de máxima importancia para nuestro tema de hoy, hemos de aludir a una carta enviada a su hermano; otra remitida a Venilón, al no poder asistir a una reunión de obispos, presidida por el propio Venilón, y en la que proponía cuatro «contraproposiciones» a las propuestas por Hincmaro, que serían posteriormente aprobadas en el ya citado Concilio Valentino. También escribió un Florilegium ex Sacra Scriptura, con textos bíblicos, alusivos a diferentes temas sacerdotales; un Breviarium Psalterii, con textos del Psalterio para momentos de tribulación 0 angustia, $o$, incluso, para suplir en determinadas circunstancias, el rezo del breviario. Quiso también contribuir a la historia con unos Annales, considerados como una continuación de los Annales Bertinianos, desde el año 835 al 861. Murió, según parece, hacia el año 861. Su vida fue escrita por el Abate Breyer, -París, 1625-: Vida de Prudencio Galindo.

\subsection{La doctrina de Prudencio}

Se encuentra expuesta en dos obras fundamentales. A ellas nos vamos a referir por separado, haciendo una síntesis de su pensamiento y del recorrido de su argumentación.

\subsubsection{Ad Hincmarum}

Trece capítulos en un total de 37 columnas configuran la carta. El primero es una simple presentación y saludo, aludiendo al tono amigable con que piensa expresarse. Los dos capítulos que siguen son una especie de preparación psicológica y doctrinal, en los que se dedica a ponderar la persona y la obra de San Agustín, haciendo ver cómo su doctrina ha sido desde siempre aceptada por la Iglesia y respaldada por otros santos, como San Fulgencio o San Próspero. Los capítulos 
cuarto y quinto son los más polémicos, dado que es donde Prudencio expone casi lacónicamente sus propias tesis y argumentos, básicamente coincidentes con las proposiciones de Gotescalco. Los siguientes ocho capítulos son un bombardeo de textos de autoridad en los que se atrinchera para fundamentar sus afirmaciones; los más extensos y reiterativos son, como era de esperar, los de San Agustín, al que le dedica diez columnas ininterrumpidas. La conclusión sería que, el no aceptar su doctrina equivaldría a rechazar la de San Agustín; pero, admitir la doctrina de San Agustín sobre estos puntos, implica el no poder condenar ni su doctrina ni la de Gotescalco. El capítulo trece y último, lo dedica a la gracia y el libre albedrío.

Los puntos básicos, junto con el correspondiente razonamiento, expuestos en los capítulos IV y V, como se ha indicado, son:

$1^{\circ}$ ) Los «réprobos» también han sido predestinados. Luego hay una doble predestinación, dado que la de los que se salvan nadie la pone en duda. La razón se encuentra en que Dios creó al hombre con una alma racional, adornada con un albedrío que, con la ayuda de la gracia, podría conseguir no morir, pero que, de abusar pertinazmente de dicho albedrío, se perdería irremisible y justísimamente. Toda la masa del género humano estaba condenada por la desobediencia de los primeros progenitores; pero Dios «conoció y predestinó» a los que por su omnipotencia y la gracia de Cristo, misericordiosamente iba a separar de «la masa» y salvar, como, igualmente «conoció y predestinó» a los que, justísimamente, al no segregarlos de «la masa», se iban a condenar.

$\left.2^{\circ}\right)$ Cristo sólo ha muerto por los elegidos. Prudencio cita los textos de los tres evangelios sinópticos, aludiendo a las palabras de la institución de la Eucaristía: «Este es mi cuerpo, ésta es mi sangre, que se derramará por vosotros y por muchos», concluyendo: luego, «no por todos, sino por muchos; no por otros, sino por vosotros».

$\left.3^{\circ}\right)$ No es voluntad de Dios que todos los hombres se salven. Es una consecuencia de lo anterior, aunque suena bastante más dura. Prudencio trae a la memoria la frase de San Pablo a Timoteo, — «que quiere que todos los hombres se salven y lleguen al conocimiento de la verdad»-, para enseguida aclarar: ese «todos» no está empleado en un sentido general, «generaliter», sino, únicamente, en un sentido especial, «specialiter», es decir, que Dios quiere que se salven «todos los que se van a salvar», pero de ninguna manera, quiere que todos absolutamente se salven. De lo contrario, ¿dónde está su omnipotencia? ¿Cómo aceptar las frases de la Escritura, donde asegura que «todo lo que Dios quiso, lo hizo en el cielo, en la tierra y en el mar»? Pero, de entenderlo en el sentido restringido, - «specialiter»-, adquieren todo su valor las expresiones evangélicas que nos son tan familiares como el que "nadie viene a mí si mi Padre no lo trae», o que "el Hijo vivifica a los que quiere», o que «el Espíritu sopla donde quiere», pero de ningún modo el Padre «trae a todos», ni el «Hijo vivifica a todos», ni el «Espíritu sopla por todas partes». Lo único es que nosotros no entendemos, ni podemos entender el modo de actuar de Dios; pero, desde luego, tampoco tenemos derecho a pedirle cuentas o a indagar en sus decretos: «sus juicios son incomprensibles; sus caminos, inexcrutables».

En conclusión: que «si todo lo que quiso, lo hizo, y quiere que todos los hombres se salven, hay que decir que no hizo lo que no quiso; y a los que no salva, es que no quiso salvarlos».

El escándalo y el desgarrarse de las vestiduras no se hizo esperar. A Hincmaro le faltó tiempo para remitir la carta a Rabano Mauro, quien advierte que, si bien hay muchos testimonios de Santos 
Padres en la carta de Prudencio, con los que está de acuerdo, no obstante hay puntos con los que no puede estar de acuerdo, como el de que «Dios con su predestinación, conduce a los elegidos al premio eterno, mientras que empuja a los pecadores a su ruina». Tanto más cuanto que parece ser que «quiere que creamos y confesemos, junto con Gotescalco, la doble predestinación [...] que nunca he leido en las Escrituras, y con la que no estoy de acuerdo». Tal vez, tampoco nosotros to estemos. No obstante, es preciso matizar; y lo vamos a hacer con palabras del propio Prudencio.

En primer lugar, con respecto al primer punto, es preciso decir que, según Prudencio, Dios no predestina a los pecadores a que pequen, sino que, supuesto que se mantengan pertinazmente en el pecado, no tiene Dios más remedio que, supuesto que El todo lo ve y conoce con anterioridad, destinarlos a lo que ellos mismos con sus obras se han buscado. Es lo que diríamos que Dios los predestina, «post praevisa merita», y en el caso de no querer rectificar. He aquí sus palabras:

Predestinó, digo, esto es, preordenó, no a que pecasen, sino a que, supuesto el pecado, cayeran en las penas eternas; predestinó, pues, es decir; preordenó, no a la culpa, sino a la pena; no para que quisieran o admitiesen el mal, sino para que, por culpa del mal que ellos deciden hacer; sean condenados justamente a la pena eterna. ${ }^{8}$

Puestas así las cosas, no parece que esté desconectada, ni mucho menos, la libertad de la predestinación; dado que, podemos incluso interpretar que es la propia libertad la que toma la decisión última. Claro que esto lo matizará, también apoyado en San Agustín, con la aclaración del libre albedrío y la gracia, ya al final de la epístola, en el capítulo trece, como dije.

En cuanto al segundo punto, — «que Cristo sólo murió por los elegidos»-, hay que entenderlo, según los testimonios aportados, en un sentido de eficacia, no de suficiencia. Cristo ha muerto realmente por todos, si bien, la eficacia de su muerte sólo ha repercutido en los que reciben la gracia y se salvan. Y aquí mismo se encuentra la contestación al tercer punto, dado que la voluntad de Dios es que todos, sin excepción se salven, pero, supuesta la posibilidad de rechazar la gracia, y aquí de nuevo el tema inevitable del libre albedrío, de hecho, esa voluntad de Dios, ese deseo, no es plenamente eficaz, sino meramente suficiente, dado que Dios a nadie le niega la gracia, aunque, igualmente puede concluirse que a nadie coacciona. Pues como dice en el ya citado capítulo trece (col. 1006), "para verse libre de la justicia, es decir para hacer el mal, basta con el libre albedrí; pero verse libre del pecado no se consigue, si no es por la gracia».

Y es que la libertad, según la doctrina agustiniana, se perdió por el pecado en el paraíso, quedándonos exclusivamente el libre albedrío, que es lo que va adjunto y le es inevitablemente debido a la naturaleza humana. Ahora bien, el libre albedrío, que es capaz de elegir, es decir, de tomar decisiones, sólo lo puede hacer para el mal. Para poder elegir el bien, le es necesaria la gracia: la gracia, al sumarse al libre albedrío, consigue que éste se transforme en libertad, pudiendo, a partir de ese momento elegir el bien. Evidentemente, sin libre albedrío no hay posibilidad de conseguir esa transformación en libertad; pero, supuesta la gracia y, consiguientemente, la libertad, sí que puede volver a elegirse el mal. Es decir, que la gracia es absolutamente necesaria para hacer el bien, pero no siempre es absolutamente suficiente, a menos que se trate de una gracia eficaz. Con palabras de San Agustín, dice en la columna 1008: 
Así pues, es cierto que nosotros tenemos libre albedrio para poder hacer el bien y el mal; ahora bien, para hacer el mal, cualquiera es libre de la justicia y siervo del pecado; sin embargo, para el bien, nadie puede ser libre, a menos que haya sido liberado por aquél que dijo: si os hubiere liberado el Hijo, entonces seréis verdaderamente libres.

Y, unas líneas más abajo, con sus propias palabras, aclarando una frase del Exodo, — «nadie por símismo es inocente ante Tì-, dice:

La misericordia divina actúa primero en nosotros sin nosotros, para que secundándola nuestro libre albedrío, haga juntamente con nosotros el bien que habíamos deseado, aunque no obstante, por tan altísima gracia, en el juicio final, nos remunerará como si todo hubiese provenido de nosotros solos.

Parece, pues, que no deja a un lado el libre albedrío, aunque, al igual que San Agustín una vez más, tampoco pueda olvidar la gracia. Idea que repite en el primero de los cuatro puntos remitidos a Venilón en su concisa Epistola Tractoria:

Confesemos estar de acuerdo con que el libre albedrio, perdido en Adán por culpa de una desobediencia, nos fue devuelto y liberado por nuestro Señor Jesucristo [...], pero que, eso no obstante, para cualquier obra buena necesitamos de la gracia de Dios omnipotente». ${ }^{9}$

Por lo que respecta al último punto, a saber «la voluntad salvífica universal de Dios», hay que advertir el peligro que conllevaba en aquellos momentos dar la impresión de que se estaba aceptando implícitamente, al menos, la tesis defendida por Orígenes y resucitada por Escoto, sobre que, de hecho, todos los hombres se van a salvar, como apuntaremos en el tratado siguiente, al referirnos a las tesis de Escoto combatidas por Prudencio.

\subsubsection{Contra Scotum}

Observemos, de entrada, la diferente expresión empleada por Prudencio. Al dirigirse a Hincmaro que, como se apuntó anteriormente, lo hacía de modo amigable, pone como título: Epístola a Hincmaro y Pardulo; ahora, en cambio, presenta la hostilidad desde el encabezamiento: Sobre la predestinación «contra» J. Escoto; y para que no haya dudas de a quién va remitido el escrito, añade, de sobrenombre Erígena. Y junto al rótulo de la dedicatoria, sus primeras palabras son: «tus blasfemias y tu descaro, oh Juan, con que te has desatado insolente contra la gracia gratuita de Dios y que, con la excusa de un cierto Gotescalco has inferido a todos los católicos, tanto más me han dolido cuanto más familiarmente te aceptaba».

La obra consta de diecinueve capítulos. Los mismos que el tratado de Escoto, al que va respondiendo detalladamente, corrigiéndolo sin miramientos, punto por punto. No es del caso el que vayamos nosotros paso a paso. Tendremos que contentarnos con aportar las tesis y razonamientos de Escoto que más afectan a las tesis fundamentales de Prudencio, y que todos confluyen y se sin- 
tetizan en la negación de la doble predestinación defendida por Gotescalco y Prudencio, que pretende demostrar con innumerables argumentos. Lo único es que Escoto, indirectamente, busca ir más lejos, presentando sutilmente la tesis de Orígenes a la que acabamos de aludir. Aquí es donde se encuentra «aquella máquina de guerra» que dice Menéndez y Pelayo, que «procuró neutralizar»nuestro Prudencio.

La primera, pues, y principal proposición de Escoto es la siguiente: «No es posible una doble predestinación». Las razones que aporta son múltiples: porque la predestinación, como la presciencia o la voluntad de Dios, se identifica con su absoluta simplicidad y unicidad de sustancia y naturaleza; porque en la Sagrada Escritura no se habla sino de una sola predestinación: la de los santos; y que, incluso, el término suele emplearse de modo abusivo y casi metafóricamente.

De aquí pasa a intentar demostrar que no hay predestinación para el infierno, sencillamente porque Dios no puede predestinar para la pena ni para la culpa, dado que ambas son pura negación de ser, a lo que Dios no puede atender; además porque Dios no puede destruir lo que creó, o lo que de algún modo pertenece a su naturaleza, -no olvidemos la visión panteísta de Escoto--. En consecuencia, si sólo hay una predestinación, —a la vida eterna-, quiere decirse que Dios, tarde 0 temprano, arreglará las cosas de modo que todos nos encontremos salvados, - aquí la tesis origenista-, y sea una realidad el que Dios quiera, -y de modo eficaz, por cierto-, la salvación de todos los hombres.

Prudencio por su parte se ratifica en su postura, desbaratando uno por uno todos los argumentos, tanto de razón, como de la Escritura o de San Agustín aportados por Escoto, reafirmándose con más contundencia en su propia doctrina, y distinguiendo la presciencia de la predestinación. El punto básico donde se apoya fuerte Prudencio es en la distinción entre culpa y pena. Así, no acepta la identidad entre presciencia y predestinación, porque «a pesar de prever el pecado, no predestina a él». Consecuentemente, El no castiga, ni puede castigar nunca aquello que hizo, dado que el pecado no puede haber sido hecho por él; de ahí que su predestinación no es tampoco a la culpa, a la que jamás puede Dios predestinar, sino a la pena que de la culpa se deriva. Doble predestinación, pues: «unos a la vida, por misericordia gratuita de Dios; otros, a los que conoció con anterioridad, a la pena, —a la pena, que no a la culpa—, por inescrutable justicia del mismo Dios» ${ }^{10}$

\subsection{Resumen y conclusiones}

Sobre la doctrina de Prudencio, hacer notar, en primer lugar, su interés por darlo todo a Dios, -gracia, predestinación—; pero, al mismo tiempo, su afán por separar la culpa de la pena, haciendo intervenir el libre albedrío en lo tocante a la decisión de pecar, y sólo la consecuente acción divina, al ser coherente con el castigo que se deriva de una culpa «libremente» elegida y realizada. Las dudas, los titubeos, la falta de claridad terminológica, propia del momento, y compartida con el mismo San Agustín, fuente original de la doctrina de la que todos quieren apropiarse, y que no admite una interpretación unívoca, como constatamos a lo largo de la historia, ya que, tanto Erígena como Gotescalco o Prudencio Galindo; tanto Lutero o Báñez como Molina, ya en pleno Renacimiento, quieren apropiársela, y la citan con frecuencia. 
Lo que no deja lugar a dudas es que el tema ha interesado en todo tiempo; y que Prudencio buscó una defensa del dogma y de la gracia, oponiéndose con la razón y las escrituras a lo que se suponía doctrina filosófica no menos que teológica. Digno de especial mención es el texto en el que aplaude la bondad de Dios, haciendo ver que, a pesar de no poder nada si no es con la gracia divina, Dios no nos lo va a echar en cara, sino que nos premiará «como si todo hubiese venido de nosotros solos».

Zigzagueo que nos puede inclinar a pensar en intransigencia, en estar rozando la heterodoxia, ya ha habido quien ha querido condenar a Prudencio. Los textos son confusoș, como confusa la terminología y la postura por inclinarse a un frente o a otro; buscando el equilibrio, la ortodoxia, el entronque con la tradición [...] Pero es que todo resulta equívoco, ambiguo, paradójico, antinómico.

El haber encontrado en su momento a un personaje como Escoto que, si bien era considerado un gran sabio, no es menos cierto que no resultó demasiado simpático ni, por supuesto, ortodoxo, -sus propios discípulos se encargaron de asesinarlo sádicamente, y la Iglèsia lo rechazó por panteísta y origenista-, supuso el trampolín más adecuado para Prudencio, quien, gracias a su postura antiescotista, podía grangearse más fácilmente la aprobación de su doctrina. Esto no obstante, la doctrina de Prudencio tampoco queda demasiado nítida; y muchas de sus expresiones sonaron con un cierto deje herético, por lo que tuvo que matizar, repitiendo una y otra vez la distinción entre pena y culpa, intentando hacer patente que Dios no tiene nada que ver con el pecado, y que si predestina al infierno, no es sino como una consecuencia inevitable del pecado al que no quiere renunciar el pecador, que lo elige y lo mantiene, gracias a su libre albedrío.

En cualquier caso, en el siglo IX, -Prudencio vs. Escoto o Hincmaro-, como en el IV, Agustín vs. maniqueos o pelagianos-, o en el XVI, -Lutero vs. Erasmo; Báñez vs. Molina一, esta doctrina se mantiene siempre en base a la dialéctica de los opuestos que, contradiciéndose, mantiene en órbita una doctrina siempre misteriosa y siempre ligada a la fe; - - teológica o filosófica-, para que, tanto la teoría como la actitud, esté en todo momento ligada a una opción de corte personal y comprometido.

Marcelino Ocaña García Facultad de Filosofía Universidad Complutense de Madrid Ciudad Universitaria 28040 Madrid 